\title{
Dose-dependent cholesterol-lowering effects of phytosterol/phytostanol-enriched margarine in statin users and statin non-users under free-living conditions
}

\author{
Simone RBM Eussen ${ }^{1,2}$, Nynke de Jong ${ }^{2}$, Cathy JM Rompelberg ${ }^{2}$, Johan Garssen ${ }^{1}$, \\ WM Monique Verschuren ${ }^{2}$ and Olaf $\mathrm{H}_{\text {Klungel }}{ }^{1, *}$ \\ 'Utrecht Institute for Pharmaceutical Sciences, PO Box 80082, 3508 TB Utrecht, The Netherlands: ${ }^{2}$ National \\ Institute for Public Health and the Environment (RIVM), Bilthoven, The Netherlands
}

Submitted 20 July 2010: Accepted 19 January 2011: First published online 28 February 2011

\begin{abstract}
Objective: To assess the effectiveness (extent to which an intervention works in daily medical practice) of the use of phytosterol/phytostanol-enriched margarines to lower total and non-HDL cholesterol levels in users and non-users of statins. Design: Retrospective cohort study.

Setting: Data were obtained from questionnaires on health and food intake from a population-based longitudinal cohort linked to pharmacy-dispensing records.

Subjects: The analysis included 3829 men and women (aged 31-71 years) who were examined during 1998-2002 and re-examined at 5-year follow-up during 2003-2007.

Results: Recommended doses of margarines were consumed by only $9 \%$ of the subjects. Serum total cholesterol decreased by respectively $-0 \cdot 16$ (95\% CI $-0 \cdot 26$, $-0.05) \mathrm{mmol} / \mathrm{l},-1.40(95 \% \mathrm{CI}-1.51,-1.30) \mathrm{mmol} / \mathrm{l}$ and $-1.64(95 \% \mathrm{CI}-1.91$, $-1 \cdot 37) \mathrm{mmol} / \mathrm{l}$ in subjects who started to use phytosterols/phytostanols only, statins only or a combination of both compounds at some point in time between examination and re-examination, compared with subjects who did not start using phytosterols/phytostanols or statins. Cholesterol-lowering effects of the phytosterols/phytostanols were similar in statin users and statin non-users and increased with increasing intake of enriched margarine (no intake, 0; low intake, $-0 \cdot 017(95 \% \mathrm{CI}-0 \cdot 16,0 \cdot 13) \mathrm{mmol} / \mathrm{l}$; medium intake, $-0 \cdot 089$ (95\% CI $-0 \cdot 22$, 0.038) $\mathrm{mmol} / \mathrm{l}$; high intake, $-0.32(95 \% \mathrm{CI}-0 \cdot 50,-0 \cdot 14) \mathrm{mmol} / \mathrm{l})$.

Conclusions: Although recommended intake levels of the enriched margarines were not reached by all persons, these data show that under customary conditions of use phytosterols/phytostanols are effective in lowering cholesterol levels in both statin users and non-users.
\end{abstract}

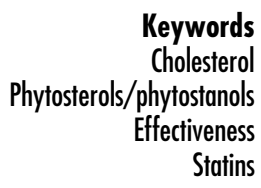

Keywords phytostanols Statins
Patients with elevated total cholesterol (TC) and LDL cholesterol (LDL-C) levels are at high risk of developing atherosclerosis and $\mathrm{CHD}^{(1)}$. First-line treatment normally focuses on lowering LDL-C, often accomplished by the use of statins. However, growing evidence suggests that non-HDL cholesterol (non-HDL-C) is a stronger predictor of CHD death than LDL-C ${ }^{(2-7)}$. Apart from statins, changes in lifestyle factors, such as quitting smoking ${ }^{(8)}$, becoming more physically active and eating a healthy diet, can also influence LDL-C and non-HDL-C. In the last decade there has been more interest in changing dietary habits, with the appearance of functional foods. Since 1999, margarines containing phytosterols/phytostanols (phytosterols/-stanols) have become available on the US and EU market ${ }^{(9)}$. Phytosterols/-stanols, which are structurally related to cholesterol, are thought to compete with cholesterol for solubilisation into mixed micelles. This leads to a reduced absorption of cholesterol and/or to an enhanced efflux of cholesterol back into the intestinal lumen due to a higher expression of the ABC transporter. Both mechanisms ultimately result in an increased faecal output of cholesterol $^{(10-14)}$.

Randomized controlled trials (RCT) have shown the efficacy (extent to which an intervention produces a beneficial effect under ideal conditions) of phytosterols/stanols in lowering serum cholesterol levels: it is estimated that phytosterols/-stanols reduce TC and LDL-C by roughly $6 \%$ and $10 \%$, respectively ${ }^{(15-17)}$. It has been shown that phytosterols/-stanols are equally effective when used alone as part of the diet or when used as an adjuvant to ongoing statin therapy. Adding phytosterols/stanols to statin therapy appears to be more effective than 
doubling the statin dose and, therefore, these products might especially be beneficial for persons who do not reach LDL-C goals with statin monotherapy and for those who experience side-effects from high doses of statins.

Although RCT are widely accepted as the gold standard of medical intervention research, their design may include short-term interventions, frequent follow-up visits, extensive monitoring and the use of restricted patient populations with high adherence to therapy. These factors limit extrapolation to daily practice populations ${ }^{(18,19)}$. Because of the high adherence to therapy in RCT and the fact that poor adherence is thought to contribute to the failure of patients to achieve therapy targets ${ }^{(20,21)}$, the reductions of $6 \%$ in TC as found in RCT may not be accomplished in persons who use the enriched margarines and statins under customary conditions.

The aim of the present study was to assess the effectiveness (extent to which an intervention works in daily medical practice) of the use of phytosterol/-stanol-enriched margarine in subjects using or not using statins in a real-world setting. As there are currently no standard databases available that integrate food intake and drug monitoring, data from an ongoing free-living cohort study containing information on functional food use was linked to a pharmacy-dispensing database for the purpose of the present study.

\section{Subjects and methods}

\section{Study setting}

Subjects from the Dutch Doetinchem Cohort Study and the Pharmacomorbidity-Record Linkage System (PHARMORLS) were linked using information on gender, date of birth and postcode in order to obtain information on the use of phytosterol/-stanol-enriched margarines and statins of the same subjects.

The Doetinchem Cohort Study was approved according to the guidelines of the Helsinki Declaration by the external Medical Ethics Committee of the Dutch TNO Research Institute. Linkage has been performed only for those participants who have agreed to it in their informed consent. The main objective of this ongoing cohort study is to investigate changes in lifestyle and risk factors for chronic diseases within patients over time in consecutive 5-year intervals. Details of the overall cohort study have been described elsewhere ${ }^{(22)}$. Participants who were examined between 1998 and 2002 and were re-examined at 5-year follow-up between 2003 and 2007 were included in the present analysis. On both examination days, respondents completed a general questionnaire and a validated $\mathrm{FFQ}^{(23,24)}$. The general questionnaire contained questions on demographic and lifestyle factors. The 178-item semi-quantitative FFQ assessed habitual dietary intake. Daily energy and nutrient intakes were computed using an adapted version of the 1996 computerized Dutch food composition table ${ }^{(25)}$. In addition, non-fasting blood samples were obtained on each examination day.

PHARMO-RLS comprises a database in which pharmacydispensing data are collected of a representative sample of more than 200 community pharmacies in fifty geographically defined areas in the Netherlands ${ }^{(26-28)}$. Data used for the present study were the person's age and gender, the prescribed drug, the anatomical therapeutic chemical (ATC) classification, the defined daily dose $(\mathrm{DDD})^{(29)}$, the dispensing date and the amount dispensed.

\section{Exposure definition}

The FFQ of the Doetinchem Cohort Study contained an open question on the brand name of the spread used on bread. The amount of margarine used was calculated by multiplying the number of bread slices consumed daily by the amount of margarine per slice, estimated from photographs of four differently sized portions. On each examination day, users of phytosterols/-stanols were defined as those with an intake of phytosterol/-stanolenriched margarine greater than zero. To evaluate the effects of different levels of margarine use, the average margarine intake was categorized into no, low $(>0$ to $<10 \mathrm{~g} / \mathrm{d}$ ), medium ( $\geq 10$ to $<20 \mathrm{~g} / \mathrm{d}$ ) or high $(\geq 20 \mathrm{~g} / \mathrm{d})$. This represents no, low $(>0$ to $<0.75 \mathrm{~g} / \mathrm{d}$ ), medium $(\geq 0.75$ to $<1.5 \mathrm{~g} / \mathrm{d})$ or high $(\geq 1.5 \mathrm{~g} / \mathrm{d})$ intake of phytosterols/-stanols. From the pharmacy-dispensing records, all prescriptions for statins (ATC classification C10AA) dispensed between 1 January 1998 and 1 October 2008 were selected. The type and dose of statin used were converted into a single equipotency score according to Penning-van Beest et $a l^{(30)}$. Subjects were considered to be users of statins at the examination day, re-examination day or both if they were, according to PHARMO-RLS, exposed to the drug on that specific day. Linking the Doetinchem Cohort data to PHARMO-RLS resulted in four categories of users on each examination day: (i) non-users; (ii) subjects using phytosterols/-stanols without statins; (iii) subjects using statins without phytosterols/-stanols; and (iv) subjects who combined phytosterols/-stanols and statins (combination users).

\section{Outcome definition}

TC and HDL-C were determined from non-fasting blood samples using standardized enzymatic methods ${ }^{(31)}$. Non-HDL-C was calculated as the difference between TC and HDL-C. The effectiveness of the phytosterol/-stanolenriched margarine and/or statins was assessed by the change in TC and non-HDL-C, and in the ratio of TC to HDL-C (TC:HDL-C), between the examination and the re-examination day.

\section{Potential confounding variables}

The following variables were considered as possible confounders: age, gender, BMI, waist:hip ratio (WHR), energy intake, (un)saturated and total fat intake, dietary 
cholesterol intake, alcohol intake, smoking behaviour, physical activity level, systolic and diastolic blood pressure, type 2 diabetes and educational level. Variables that altered the regression coefficient of the usage indicator variable by $\geq 10 \%$ were entered in the model as confounding factors ${ }^{(32)}$.

\section{Statistical analyses}

\section{General characteristics}

Demographic and health characteristics of the four groups of users were compared using ANOVA or the Kruskal-Wallis test for continuous variables and the $\chi^{2}$ test for nominal variables. Analyses were based on the reexamination data of the Doetinchem study (2003-2007), as the phytosterol/-stanol-enriched margarines were available on the Dutch market only from 1999 onwards.

\section{Effectiveness of phytosterols/-stanols and statins}

A general linear regression model was used to assess differences in TC change over time between subjects not using cholesterol-lowering products at any moment and subjects who started to use phytosterols/-stanols without statins, statins without phytosterols/-stanols or both compounds at some point in time between the two examination days (analysis I, see Fig. 1). Multivariate ANOVA was carried out to adjust for confounders at examination (1998-2002). All models were adjusted for cholesterol levels at examination as it has been shown that patients with high baseline cholesterol levels experience larger reductions in cholesterol levels after phytosterol/-stanol or statin intake ${ }^{(33)}$. In order to describe the cholesterol-lowering effects of the use of phytosterols/stanols more thoroughly, to include persons already using phytosterol/-stanol-enriched margarines in the years 1999-2002 and to be able to adjust for time-varying confounders, repeated-measures analysis of covariance (ANCOVA) was used (analysis II, see Fig. 1). The following fixed effects were included in the model: use of phytosterol/-stanol-enriched margarine, use of statin and time. Furthermore, an interaction term for enriched margarine and statins was entered in the model to test whether there was a difference between the effect of the enriched margarine given with statins and the effect of the enriched margarine given without statins. Use of enriched margarine was entered in the model as a dichotomous variable (yes/no), as a continuous variable (enriched margarine use in $\mathrm{g} / \mathrm{d}$ ) and as a categorical variable (no/ low/medium/high intake). Models were checked for collinearity and residuals were checked for homoscedasticity, outliers and normal distribution. Non-HDL-C and TC:HDL-C were analysed in the same way.

$P$ values were considered statistically significant at the 0.05 level. The Statistical Analysis Systems statistical software package version 9.1.3 (SAS Institute, Cary, NC, USA) was used for all analyses.

\section{Results}

\section{General characteristics}

From the linked database, complete records were available for 3829 subjects (Fig. 1). These subjects were examined in the Doetinchem Cohort Study during the years 1998-2002 and re-examined during the years 2003-2007. At re-examination, 195 (5.1\%) of these subjects used phytosterol/-stanol-enriched margarine only, whereas forty-three subjects $(1 \cdot 1 \%)$ combined the use of

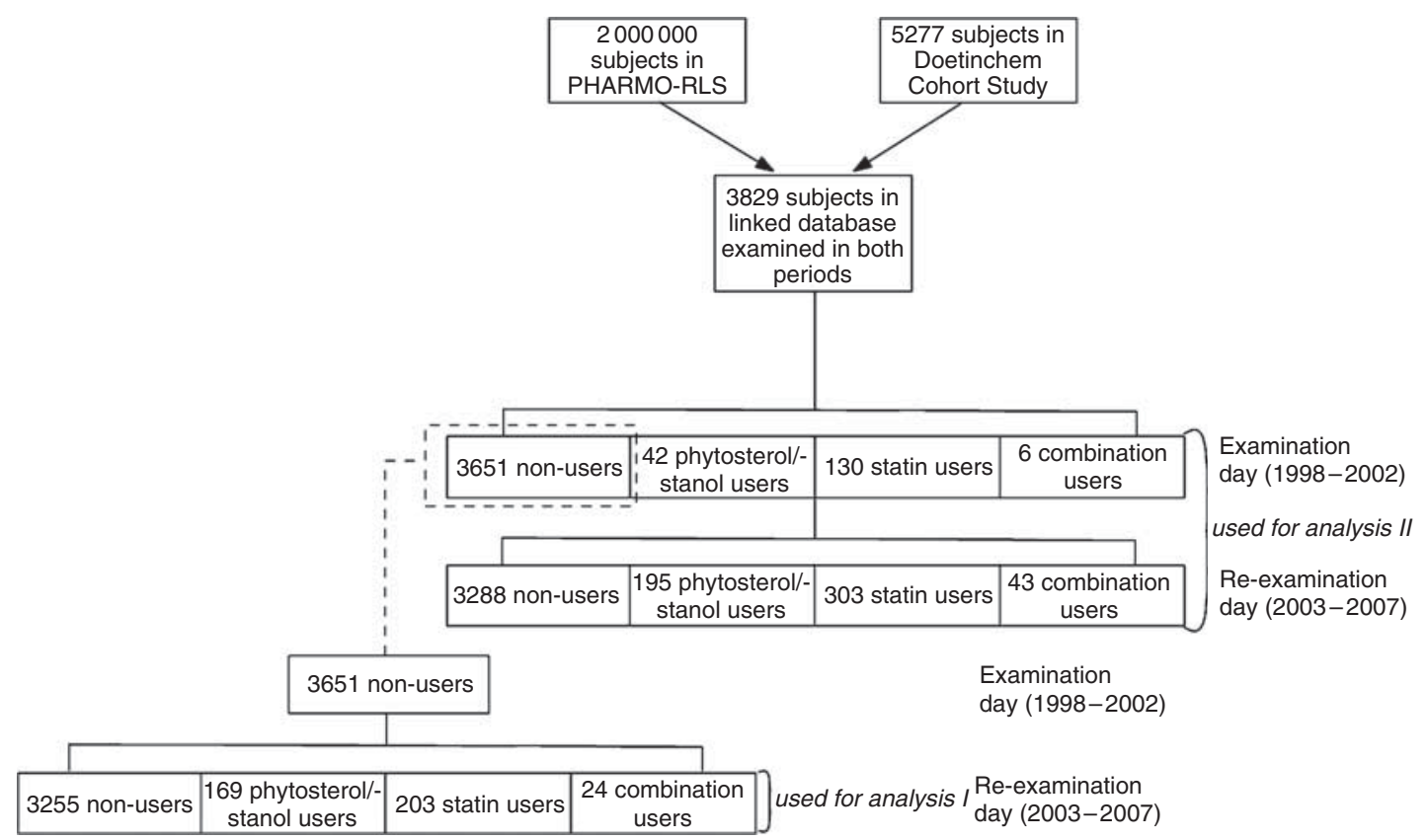

Fig. 1 Flowchart of subject numbers in the linked database used for analysis I and II 
enriched margarine with statins. A total of 303 subjects (7.9\%) used statins only.

Phytosterol/-stanol-enriched margarine, with or without statins, was more frequently used among the higher educated and phytosterol/-stanol users consumed more alcohol daily. The vast majority of subjects who used enriched margarine used phytosterol-enriched margarine (98\%). Median intake of margarine was $13 \mathrm{~g} / \mathrm{d}$, ranging from $0 \cdot 12 \mathrm{~g} / \mathrm{d}$ to $60 \mathrm{~g} / \mathrm{d}(0 \cdot 01$ to $4.5 \mathrm{~g}$ phytosterols/stanols per $d)$. There was no significant difference in intake amount between subjects who did or did not combine their phytosterol/-stanol intake with statins. Only $9 \%$ of the subjects used the recommended margarine intake of $27 \mathrm{~g} / \mathrm{d}$ ( $2 \mathrm{~g}$ phytosterols/-stanols per $\mathrm{d}$ ).

Statin users, whether or not in combination with phytosterols/-stanols, were more likely to be male, had higher WHR and perceived their health more often as moderate or poor compared with statin non-users. Users of cholesterol-lowering products, either phytosterol/stanol-enriched margarine and/or statins, were older and consumed less dietary (saturated) fat compared with nonusers (Table 1).

\section{Effectiveness of phytosterols/-stanols in statin users and statin non-users}

Table 2 presents the results of the univariate and multivariate linear regression analysis (analysis I). Calculations are based on a total of 169 phytosterol/-stanol only users, 203 statin only users, twenty-four combination users and 3255 non-users. These persons did not use phytosterol/stanol-enriched margarine or statins at examination (1998-2002) and started to use one or both of these products at some point in time during the 5-year interval until re-examination. From Table $2 \mathrm{a}$ it appears that at examination, thus before the start of phytosterols/-stanols and/or statins, mean serum TC levels of future phytosterol/stanol-enriched margarine only users were significantly higher than those of non-users $(6 \cdot 15 \mathrm{mmol} / 1 v .5 \cdot 62 \mathrm{mmol} / \mathrm{l}$, $P<0 \cdot 0001$ ), but significantly lower than those of future statin only users $(6 \cdot 15 \mathrm{mmol} / 1 v \cdot 6 \cdot 66 \mathrm{mmol} / 1, P<0 \cdot 0001)$ and combination users $(6.15 \mathrm{mmol} / 1 \quad v . \quad 6.69 \mathrm{mmol} / \mathrm{l}$, $P=0 \cdot 015)$. TC, non-HDL-C and TC:HDL-C decreased significantly during the 5-year follow-up period in all users, compared with the reference group (non-users; Table 2b). The largest difference in TC change compared with the non-users was found in combination users $(-1.64$ (95\% CI $-1.91,-1.37) \mathrm{mmol} / \mathrm{l})$, followed by statin only users $(-1.40(95 \%$ CI $-1.51,-1.30) \mathrm{mmol} / \mathrm{l})$. Statistical significance was not reached for change in TC between these groups $(P=0 \cdot 11)$, but there was a significant difference in change in non-HDL-C and TC:HDL-C between combination users and statin only users.

Results of the repeated-measures ANCOVA are shown in Table 3 (analysis II). After adjustment for age, BMI, WHR, saturated fat intake, alcohol intake, diastolic blood pressure, type 2 diabetes and statin use, the intake of phytosterols/-stanols was significantly associated with a decrease in TC of $-0 \cdot 11(95 \% \mathrm{CI}-0 \cdot 20,-0 \cdot 025) \mathrm{mmol} / \mathrm{l}$. Similarly, non-HDL-C and TC:HDL-C decreased significantly over time when phytosterols/-stanols were used. There was no evidence of an interactive effect between enriched margarine use and statin use, as the interaction term was not significant.

Each gram increase in enriched margarine use resulted in a decrease in TC of -0.0094 (95\% CI -0.014 , $-0 \cdot 0043) \mathrm{mmol} / \mathrm{l}$. Also non-HDL-C and TC:HDL-C were significantly reduced by phytosterols/-stanols. The effectiveness of phytosterols/-stanols to lower TC increased progressively across the four categories of intake amounts $(0 ;-0 \cdot 017(95 \% \mathrm{CI}-0 \cdot 16,0 \cdot 13) \mathrm{mmol} / \mathrm{l} ;-0 \cdot 089(95 \% \mathrm{CI}$ $-0 \cdot 22,0 \cdot 038) \mathrm{mmol} / \mathrm{l} ;-0.32(95 \% \mathrm{CI}-0.50,-0 \cdot 14)$ $\mathrm{mmol} / \mathrm{l})$. Similar patterns were found for non-HDL-C and TC:HDL-C, although these outcome measures were significantly reduced following an intake of $\geq 10 \mathrm{~g}$ enriched margarine per $\mathrm{d}$, whereas TC was significantly reduced only after high intake ( $\geq 20 \mathrm{~g} / \mathrm{d})$.

\section{Discussion}

Our results indicate that the use of margarine enriched with phytosterols/-stanols is effective in lowering TC, non-HDL-C and TC:HDL-C in both users and non-users of statins under free-living conditions. In the present study, serum TC decreased by respectively $0 \cdot 16 \mathrm{mmol} / \mathrm{l}$, $1.40 \mathrm{mmol} / \mathrm{l}$ and $1.64 \mathrm{mmol} / 1$ in subjects who started to use phytosterols/-stanols only, statins only or a combination of both compounds at some point in time between the examination and re-examination day, compared with subjects who did not start using phytosterols/-stanols or statins. Statistical significance was not reached for change in TC between combination users and statin only users $(P=0 \cdot 11)$, but there was a significant difference in change in non-HDL-C and TC:HDL-C between these groups. Repeated-measures ANCOVA showed slightly lower levels of effectiveness, most likely explained by the fact that the greatest reductions in cholesterol levels are achieved in subjects who started the use of the enriched margarine. The cholesterol-lowering effect of the margarine when added to statin therapy was similar to the effect observed when the margarine was used alone. This additive effect of the enriched margarine to statin therapy has also been found in prior studies ${ }^{(34,35)}$. Intake amounts above $20 \mathrm{~g}$ margarine/d ( $1.5 \mathrm{~g}$ phytosterols/-stanols per $\mathrm{d}$ ) were necessary to reduce TC significantly. In our study, only $20 \%$ of the subjects used this intake level.

In the model with continuous variables, each gram intake of margarine was associated with reductions in TC of $0.0094 \mathrm{mmol} / 1$. People who consume the recommended intake of enriched margarine of $27 \mathrm{~g} / \mathrm{d}(2 \mathrm{~g}$ phytosterols/-stanols per d) may reduce their TC level by $0.25 \mathrm{mmol} / 1(0 \cdot 0094 \mathrm{mmol} / 1 \times 27 \mathrm{~g})$, which is about $4 \%$. 
Table 1 Demographic and health characteristics of non-users, phytosterol/-stanol users, statin users and combination users in the linked database ( $n$ 3829)

\begin{tabular}{|c|c|c|c|c|c|c|c|c|}
\hline & \multicolumn{2}{|c|}{ Non-users* $(n$ 3288) } & \multicolumn{2}{|c|}{ Phytosterol/-stanol users ( $n$ 195) } & \multicolumn{2}{|c|}{ Statin users* $(n$ 303) } & \multicolumn{2}{|c|}{ Combination users $(n$ 43) } \\
\hline & Mean & SD & Mean & SD & Mean & SD & Mean & SD \\
\hline Age (years) & $55 \cdot 0^{\mathrm{a}}$ & $9 \cdot 7$ & $58 \cdot 2^{\mathrm{b}}$ & $7 \cdot 7$ & $62 \cdot 7^{\mathrm{c}}$ & $7 \cdot 5$ & $60 \cdot 9^{c}$ & 8.5 \\
\hline WHR & $0.91^{\mathrm{a}}$ & 0.08 & $0.91^{\mathrm{a}}$ & 0.08 & $0.95^{\mathrm{b}}$ & 0.08 & $0.93^{\mathrm{b}}$ & 0.07 \\
\hline \multicolumn{9}{|l|}{ Blood pressure } \\
\hline Systolic $(\mathrm{mmHg})$ & $134 \cdot 6^{\mathrm{a}}$ & $18 \cdot 6$ & $139 \cdot 6^{\mathrm{b}}$ & $18 \cdot 6$ & $142 \cdot 0^{\mathrm{b}}$ & $20 \cdot 8$ & $140 \cdot 7^{b}$ & $13 \cdot 6$ \\
\hline Diastolic (mmHg) & $84 \cdot 9^{\mathrm{a}}$ & $10 \cdot 2$ & $87 \cdot 6^{\mathrm{b}}$ & $10 \cdot 6$ & $85 \cdot 4^{a}$ & $9 \cdot 9$ & $87 \cdot 4^{\mathrm{a}, \mathrm{b}}$ & $9 \cdot 1$ \\
\hline \multicolumn{9}{|l|}{ Dietary fat intake } \\
\hline Total fat (\% of energy) & $35 \cdot 7^{\mathrm{a}}$ & $5 \cdot 0$ & $32 \cdot 7^{\mathrm{b}}$ & $5 \cdot 0$ & $34 \cdot 9^{c}$ & $4 \cdot 7$ & $33 \cdot 7^{\mathrm{b}, \mathrm{c}}$ & $4 \cdot 7$ \\
\hline \multirow[t]{2}{*}{ Saturated fat (\% of energy) } & $14 \cdot 3^{a}$ & $2 \cdot 5$ & $13 \cdot 0^{b}$ & $2 \cdot 2$ & $13 \cdot 7^{c}$ & $2 \cdot 3$ & $13 \cdot 0^{\mathrm{b}, \mathrm{c}}$ & $2 \cdot 0$ \\
\hline & Median & Range & Median & Range & Median & Range & Median & Range \\
\hline BMI $\left(\mathrm{kg} / \mathrm{m}^{2}\right)$ & $25 \cdot 9^{a}$ & $23 \cdot 7-28 \cdot 5$ & $26 \cdot 0^{a}$ & $23 \cdot 7-28 \cdot 3$ & $27 \cdot 4^{b}$ & $25 \cdot 2-29 \cdot 8$ & $27 \cdot 7^{\mathrm{a}, \mathrm{b}}$ & $24 \cdot 8-29 \cdot 4$ \\
\hline \multicolumn{9}{|l|}{ Dietary intake } \\
\hline Energy $(\mathrm{MJ} / \mathrm{d})$ & $8 \cdot 56^{\mathrm{a}}$ & $7 \cdot 28-10 \cdot 1$ & $8 \cdot 22^{b}$ & $6 \cdot 79-9.59$ & $8 \cdot 00^{\mathrm{b}}$ & $6 \cdot 67-9 \cdot 19$ & $8 \cdot 25^{a, b}$ & $6 \cdot 37-9 \cdot 84$ \\
\hline Total fat $(\mathrm{g} / \mathrm{d})$ & $80 \cdot 1^{\mathrm{a}}$ & $65 \cdot 2-98 \cdot 3$ & $71 \cdot 0^{\mathrm{b}}$ & $54 \cdot 8-83 \cdot 4$ & $73 \cdot 0^{\mathrm{b}}$ & $61 \cdot 0-88 \cdot 0$ & $73 \cdot 3^{\mathrm{b}}$ & $58 \cdot 8-89 \cdot 9$ \\
\hline Monounsaturated fat $(\mathrm{g} / \mathrm{d})$ & $31 \cdot 1^{a}$ & $24 \cdot 9-38 \cdot 0$ & $27 \cdot 2^{\mathrm{b}}$ & $21 \cdot 3-32 \cdot 7$ & $27 \cdot 5^{\mathrm{b}}$ & $22 \cdot 5-34 \cdot 1$ & $26 \cdot 7^{\mathrm{b}}$ & $22 \cdot 3-34 \cdot 0$ \\
\hline Polyunsaturated fat $(\mathrm{g} / \mathrm{d})$ & $15 \cdot 9^{a}$ & $12 \cdot 5-20 \cdot 3$ & $14 \cdot 1^{\mathrm{b}}$ & $10 \cdot 7-17 \cdot 0$ & $15 \cdot 4^{\mathrm{a}}$ & $12 \cdot 1-20 \cdot 2$ & $15 \cdot 7^{\mathrm{a}, \mathrm{b}}$ & $12 \cdot 3-18 \cdot 8$ \\
\hline Saturated fat $(\mathrm{g} / \mathrm{d})$ & $32 \cdot 1^{a}$ & $25 \cdot 7-39 \cdot 7$ & $28 \cdot 1^{b}$ & $22 \cdot 7-33 \cdot 7$ & $28 \cdot 8^{b}$ & $23 \cdot 4-33 \cdot 9$ & $28 \cdot 8^{\mathrm{b}}$ & $21 \cdot 4-33 \cdot 5$ \\
\hline Cholesterol $(\mathrm{mg} / \mathrm{d})$ & $212^{\mathrm{a}}$ & $172-263$ & $195^{\mathrm{b}}$ & $156-232$ & $206^{\mathrm{b}}$ & $163-249$ & $211^{a, b}$ & $179-271$ \\
\hline Alcohol $(\mathrm{g} / \mathrm{d})$ & $7 \cdot 4^{a}$ & $1 \cdot 4-18 \cdot 7$ & $11 \cdot 4^{\mathrm{b}}$ & $2 \cdot 9-24 \cdot 1$ & $7 \cdot 1^{a}$ & $1 \cdot 0-20 \cdot 0$ & $11 \cdot 1^{\mathrm{b}}$ & $3 \cdot 7-24 \cdot 2$ \\
\hline \multirow[t]{2}{*}{ Phytosterol/-stanol-enriched margarine intake $(\mathrm{g} / \mathrm{d})$} & \multicolumn{2}{|r|}{ NA } & $13 \cdot 2$ & $7 \cdot 77-18 \cdot 5$ & \multicolumn{2}{|r|}{ NA } & $13 \cdot 1$ & $8 \cdot 41-17 \cdot 7$ \\
\hline & \multicolumn{2}{|r|}{$\%$} & \multicolumn{2}{|c|}{$\%$} & \multicolumn{2}{|r|}{$\%$} & \multicolumn{2}{|c|}{$\%$} \\
\hline Male gender & \multicolumn{2}{|r|}{$48^{a, b}$} & \multicolumn{2}{|c|}{$44^{a}$} & \multicolumn{2}{|r|}{$56^{c}$} & \multicolumn{2}{|c|}{$63^{b, c}$} \\
\hline Low education level & \multirow{2}{*}{\multicolumn{2}{|c|}{$48^{\mathrm{a}}$}} & \multicolumn{2}{|c|}{$39^{\mathrm{b}}$} & \multirow{2}{*}{\multicolumn{2}{|c|}{$55^{\mathrm{c}}$}} & \multicolumn{2}{|c|}{$44^{\mathrm{a}, \mathrm{b}, \mathrm{c}}$} \\
\hline History of CVD & & & \multirow{2}{*}{\multicolumn{2}{|c|}{$\begin{array}{r}3^{\mathrm{a}} \\
47^{\mathrm{b}}\end{array}$}} & & & & \\
\hline Family history of CVD & \multicolumn{2}{|r|}{$33^{\mathrm{a}}$} & & & & $43^{\mathrm{b}}$ & & \\
\hline Co-morbidities & & & & & & & & \\
\hline Hypertension & & $30^{\mathrm{a}}$ & & & & $59^{c}$ & & \\
\hline Diabetes mellitus & & $3^{a}$ & & & & $23^{c}$ & & \\
\hline Asthma & & 4 & & & & 5 & & \\
\hline Ever diagnosed with $\mathrm{HC}$ & & $16^{\mathrm{a}}$ & & & & $90^{c}$ & & \\
\hline Currently smoking & & $21^{\mathrm{a}}$ & & & & $17^{\mathrm{a}, \mathrm{b}}$ & & \\
\hline Moderate/poor self-perceived health & & $13^{\mathrm{a}}$ & & & & $24^{\mathrm{b}}$ & & \\
\hline Low physical activity pattern & & 18 & & & & 18 & & \\
\hline Statin & & & & & & & & \\
\hline Simvastatin & & NA & & & & 46 & & \\
\hline Pravastatin & & NA & & & & 14 & & \\
\hline Atorvastatin & & NA & & & & 31 & & \\
\hline Fluvastatin/rosuvastatin & & NA & & & & 9 & & \\
\hline
\end{tabular}

WHR, waist:hip ratio; HC, hypercholesterolemia; NA, not applicable.

.

*Numbers vary due to missing values. 
Table 2 (a) Serum cholesterol levels at examination (1998-2002) and (b) change in cholesterol levels between examination (1998-2002) and re-examination (2003-2007) day in subjects who started to use phytosterols/-stanols without statins ( $n$ 169), statins without phytosterols/-stanols $(n 203)$ or a combination of both compounds $(n 24)$ between examination and re-examination, as compared with subjects who did not start using phytosterols/-stanols or statins (non-users, $n$ 3255) (analysis I). Data from the linked database

(a) Serum cholesterol levels at examination (1998-2002)

\begin{tabular}{|c|c|c|c|c|c|c|c|c|}
\hline & \multicolumn{2}{|c|}{$\begin{array}{c}\text { Non-users (reference) } \\
(n \text { 3255) }\end{array}$} & \multicolumn{2}{|c|}{$\begin{array}{l}\text { Phytosterol/-stanol users } \\
\qquad(n \text { 169) }\end{array}$} & \multicolumn{2}{|c|}{$\begin{array}{l}\text { Statin users } \\
\quad(n \text { 203) }\end{array}$} & \multicolumn{2}{|c|}{$\begin{array}{l}\text { Combination users } \\
\qquad(n 24)\end{array}$} \\
\hline & Mean & SD & Mean & SD & Mean & SD & Mean & SD \\
\hline \multicolumn{9}{|l|}{ TC $(\mathrm{mmol} / \mathrm{l})$} \\
\hline At examination & $5 \cdot 62^{\mathrm{a}}$ & 0.98 & $6 \cdot 15^{\mathrm{b}}$ & 1.00 & $6 \cdot 66^{\mathrm{c}}$ & $1 \cdot 23$ & $6 \cdot 69^{c}$ & $1 \cdot 05$ \\
\hline \multicolumn{9}{|l|}{ Non-HDL-C (mmol/l) } \\
\hline \multicolumn{7}{|l|}{ TC:HDL-C } & & 0.98 \\
\hline At examination & $4 \cdot 39^{\mathrm{a}}$ & $1 \cdot 51$ & $4 \cdot 74^{\mathrm{b}}$ & 1.54 & $5 \cdot 80^{\mathrm{C}}$ & $1 \cdot 78$ & $5.97^{\mathrm{C}}$ & 1.97 \\
\hline
\end{tabular}

(b) Change in cholesterol levels between examination (1998-2002) and re-examination (2003-2007) day

\begin{tabular}{|c|c|c|c|c|c|c|c|c|c|c|c|c|c|c|}
\hline & \multicolumn{2}{|c|}{$\begin{array}{c}\text { Non-users (reference) } \\
\text { (n 3255) }\end{array}$} & \multicolumn{4}{|c|}{$\begin{array}{l}\text { Phytosterol/-stanol users } \\
\qquad(n \text { 169) }\end{array}$} & \multicolumn{4}{|c|}{$\begin{array}{l}\text { Statin users } \\
\quad(n \text { 203) }\end{array}$} & \multicolumn{4}{|c|}{$\begin{array}{l}\text { Combination users } \\
\qquad(n 24)\end{array}$} \\
\hline & \multirow{2}{*}{$\begin{array}{l}\text { Crude* }^{*} \\
\text { Mean }\end{array}$} & \multirow{2}{*}{$\begin{array}{c}\text { Adjustedt } \\
95 \% \mathrm{Cl}\end{array}$} & \multicolumn{2}{|r|}{ Crude $^{*}$} & \multicolumn{2}{|r|}{ Adjustedt } & \multicolumn{2}{|r|}{ Crude* $^{*}$} & \multicolumn{2}{|r|}{ Adjustedt } & \multicolumn{2}{|r|}{ Crude $^{*}$} & \multicolumn{2}{|c|}{ Adjustedt } \\
\hline & & & Mean & $95 \% \mathrm{Cl}$ & Mean & $95 \% \mathrm{Cl}$ & Mean & $95 \% \mathrm{Cl}$ & Mean & $95 \% \mathrm{Cl}$ & Mean & $95 \% \mathrm{Cl}$ & Mean & $95 \% \mathrm{Cl}$ \\
\hline $\begin{array}{l}\text { TC (mmol/l) } \\
5 \text {-year difference } \\
\text { Non-HDL-C (mmol/l) }\end{array}$ & $0^{\mathrm{a}}$ & $0^{\mathrm{a}}$ & $-0 \cdot 13^{b}$ & $-0.24,-0.024$ & $-0 \cdot 16^{b}$ & $-0.26,-0.050$ & $-1 \cdot 43^{\mathrm{c}}$ & $-1 \cdot 53,-1 \cdot 33$ & $-1 \cdot 40^{c}$ & $-1 \cdot 51,-1 \cdot 30$ & $-1 \cdot 63^{c}$ & $-1 \cdot 91,-1 \cdot 36$ & $-1 \cdot 64^{c}$ & $-1 \cdot 91,-1 \cdot 37$ \\
\hline & $0^{\mathrm{a}}$ & $0^{\mathrm{a}}$ & $-0 \cdot 17^{b}$ & $-0.28,-0.067$ & $-0 \cdot 18^{b}$ & $-0.29,-0.077$ & $-1 \cdot 47^{c}$ & $-1 \cdot 57,-1 \cdot 37$ & $-1 \cdot 45^{c}$ & $-1 \cdot 55,-1 \cdot 35$ & $-1 \cdot 72^{d}$ & $-2 \cdot 00,-1 \cdot 45$ & $-1 \cdot 74^{d}$ & $-2 \cdot 01,-1 \cdot 46$ \\
\hline 5-year difference & $0^{\mathrm{a}}$ & $0^{\mathrm{a}}$ & $-0.21^{b}$ & $-0.34,-0.074$ & $-0 \cdot 19^{b}$ & $-0.32,-0.051$ & $-1 \cdot 33^{c}$ & $-1 \cdot 46,-1 \cdot 21$ & $-1 \cdot 29^{c}$ & $-1 \cdot 42,-1 \cdot 16$ & $-1 \cdot 72^{\mathrm{d}}$ & $-2 \cdot 07,-1 \cdot 37$ & $-1 \cdot 69^{d}$ & $-2 \cdot 04,-1 \cdot 34$ \\
\hline
\end{tabular}

TC, total cholesterol; non-HDL-C, non-HDL cholesterol.

To convert cholesterol mmoll to $\mathrm{mg} / \mathrm{dl}$, multiply by 38.7.

${ }_{a, b, c, d}$ Mean values within a row with unlike superscripts were significantly different $(P<0.05)$.

*Adjusted for cholesterol level at examination.

tAdjusted for age, BMI, waist:hip ratio, saturated fat intake, alcohol intake, diastolic blood pressure, type 2 diabetes and cholesterol level at examination. 
Table 3 Effectiveness of phytosterols/-stanols on change in TC, non-HDL-C and TC:HDL-C between examination (1998-2002) and re-examination (2003-2007), according to repeatedmeasures analysis of covariance (analysis II). Data from the linked database

\begin{tabular}{|c|c|c|c|c|c|c|c|c|c|}
\hline \multirow[b]{2}{*}{ Phytosterols/-stanols } & \multicolumn{3}{|c|}{$\mathrm{TC}(\mathrm{mmol} / \mathrm{l})$} & \multicolumn{3}{|c|}{ Non-HDL-C (mmol/l) } & \multicolumn{3}{|c|}{ TC:HDL-C } \\
\hline & $\beta$ & $95 \% \mathrm{Cl}$ & $P$ & $\beta$ & $95 \% \mathrm{Cl}$ & $P$ & $\beta$ & $95 \% \mathrm{Cl}$ & $P$ \\
\hline \multicolumn{10}{|l|}{ With use as a yes/no variable } \\
\hline Crude $^{*}$ & -0.077 & $-0 \cdot 17,0 \cdot 014$ & 0.098 & $-0 \cdot 13$ & $-0.22,-0.040$ & 0.0047 & $-0 \cdot 22$ & $-0.34,-0 \cdot 10$ & $<0.001$ \\
\hline Adjustedt & $-0 \cdot 11$ & $-0 \cdot 20,-0.025$ & 0.020 & $-0 \cdot 16$ & $-0.25,-0.072$ & $<0.001$ & -0.22 & $-0.34,-0.11$ & $<0.001$ \\
\hline \multicolumn{10}{|l|}{ With use as a continuous variable $(\mathrm{g} / \mathrm{d})$} \\
\hline Crude* & -0.0075 & $-0.013,-0.0022$ & $<0 \cdot 001$ & -0.0089 & $-0.014,-0.0036$ & 0.0010 & $-0 \cdot 011$ & $-0.018,-0.0041$ & 0.0013 \\
\hline Adjustedt & -0.0094 & $-0.014,-0.0043$ & $<0.001$ & -0.011 & $-0.016,-0.0058$ & $<0.0001$ & -0.013 & $-0.019,-0.0061$ & $<0.001$ \\
\hline \multicolumn{10}{|l|}{ With use as a categorical variable } \\
\hline \multicolumn{10}{|l|}{ Crude* } \\
\hline No intake $(0 \mathrm{~g} / \mathrm{d})$ & 0 & 0 & & 0 & 0 & & 0 & 0 & \\
\hline Low intake $(>0$ to $<10 \mathrm{~g} / \mathrm{d})$ & 0.014 & $-0 \cdot 13,0 \cdot 16$ & 0.85 & -0.061 & $-0.21,0.086$ & $0 \cdot 42$ & $-0 \cdot 18$ & $-0.37,-0.0095$ & 0.063 \\
\hline Medium intake $(\geq 10$ to $<20 \mathrm{~g} / \mathrm{d})$ & -0.058 & $-0 \cdot 19,0.074$ & 0.39 & $-0 \cdot 13$ & $-0.27,-0.0023$ & 0.046 & -0.26 & $-0.44,-0.090$ & 0.0028 \\
\hline High intake $(\geq 20 \mathrm{~g} / \mathrm{d})$ & -0.27 & $-0.46,-0.082$ & 0.0050 & $-0 \cdot 25$ & $-0.44,-0.057$ & $0 \cdot 011$ & $-0 \cdot 20$ & $-0.45,0.044$ & $0 \cdot 11$ \\
\hline \multicolumn{10}{|l|}{ Adjustedt } \\
\hline No intake $(0 \mathrm{~g} / \mathrm{d})$ & 0 & 0 & & 0 & 0 & & 0 & 0 & \\
\hline Low intake $(>0$ to $<10 \mathrm{~g} / \mathrm{d})$ & -0.017 & $-0 \cdot 16,0 \cdot 13$ & 0.82 & -0.068 & $-0.21,0.073$ & $0 \cdot 34$ & $-0 \cdot 14$ & $-0.32,0.047$ & $0 \cdot 15$ \\
\hline Medium intake $(\geq 10$ to $<20 \mathrm{~g} / \mathrm{d})$ & -0.089 & $-0.22,0.038$ & 0.17 & -0.016 & $-0.28,-0.032$ & 0.014 & -0.26 & $-0.42,-0.097$ & 0.0018 \\
\hline High intake $(\geq 20 \mathrm{~g} / \mathrm{d})$ & -0.32 & $-0.50,-0.14$ & $<0.001$ & -0.31 & $-0.49,-0.13$ & $<0.001$ & -0.29 & $-0.52,-0.051$ & 0.017 \\
\hline
\end{tabular}

TC, total cholesterol; non-HDL-C, non-HDL cholesterol.

To convert cholesterol $\mathrm{mmol} / \mathrm{l}$ to $\mathrm{mg} / \mathrm{dll}$, multiply by 38.7 .

${ }^{*}$ Adjusted for equipotency score of statin.

tAdjusted for age, BMI, waist:hip ratio, saturated fat intake, alcohol intake, diastolic blood pressure, type 2 diabetes and equipotency score of statin. 
Although no trials have investigated the direct relationship between the intake of phytosterols/-stanols and CHD risk reduction, data from RCT and prospective studies indicate that a $4 \%$ decrease in serum TC levels would reduce the incidence of CHD by approximately $10-15 \%{ }^{(36,37)}$. A recently conducted meta-analysis of RCT on the LDL-C-lowering effects of phytosterols/-stanols found that LDL-C was reduced by $0.34 \mathrm{mmol} / 1$ (or $8.8 \%$ ) for a daily intake of $2 \cdot 15 \mathrm{~g}$ phytosterols/-stanols ${ }^{(16)}$. In the present study, a daily intake of $2 \mathrm{~g}$ phytosterols/-stanols reduced LDL-C levels by approximately $0.25 \mathrm{mmol} / 1$ or $5 \%$, given that the cholesterol-lowering effect of phytosterols/-stanols affects only LDL-C and about $80 \%$ of the circulating cholesterol in the human body is carried bound to $\mathrm{LDL}^{(38)}$. This level of effect is considerably lower than the effects expected from RCT. As could be expected, effects from statins were substantially larger compared with the effects achieved by the use of enriched margarines.

In this Dutch cohort, $98 \%$ of the enriched margarine users consumed phytosterol-enriched margarine. Yet, it is reasonable to assume that our results are also applicable to countries or situations where phytostanols are more commonly used. Phytosterols and -stanols have been found to reduce cholesterol levels equally in both short ${ }^{(39-42)}$ and longer ${ }^{(43)}$ term $\mathrm{RCT}^{(16)}$, albeit it has been suggested that the cholesterol-lowering effect of phytosterols attenuates over time due to down-regulation of bile acid synthesis ${ }^{(44)}$.

Two other related studies explored the effectiveness of phytosterols/-stanols and statins in a real-life setting ${ }^{(34,45)}$. The first study did not find any significant differences in effects between cholesterol-lowering drugs only and combined intake ${ }^{(45)}$. On the other hand, phytosterols/stanols appeared to reduce cholesterol levels additively to cholesterol-lowering drugs in the second study ${ }^{(34)}$. A major limitation of these studies was the small number of combination users; only twelve and fifteen subjects combined enriched margarine and cholesterol-lowering drugs in the first and second study, respectively. Moreover, those studies did not distinguish between statins and other cholesterol-lowering drugs and questionnaires were used for the determination of drug usage. Administrative databases, such as PHARMO-RLS, have the advantage that patient-related recall bias and non-response bias are reduced, precise information about prescribed drugs can be obtained and the drug history is available over a long period. Pharmacy data have the advantage over medical records of being able to obtain information regarding what medication was acquired instead of what medication was prescribed. However, uncertainty still exists concerning whether or not the drug is actually taken. Another limitation of the present study is that no information was available about the use of other phytosterol/stanol-containing products. This might have led to an overestimation of the effect of phytosterol/-stanol-enriched margarines, as phytosterol/-stanol-enriched margarine users might be inclined to use other phytosterol/-stanolenriched products as well. In addition, no information on food intake was gathered in the 5-year interval between examination and re-examination and it should be acknowledged that this is an observational study which might be subject to residual confounding due to potential unmeasured differences in cardiovascular risk profile and patient characteristics between users and non-users of phytosterol/-stanol-enriched margarine and/or statins. The restriction of the present study to a particular area of the Netherlands might constrain the generalisability of the results. Doetinchem is a rural area in the eastern part of the Netherlands and smokers and the lower educated appear to be under-represented in the cohort. However, although it is conceivable that this affects the number of subjects using enriched margarine or the baseline lipid values, it is unlikely that it has an influence on the estimated associations.

For the purpose of the study, a database was used which included pharmacy-dispensing data and questionnaire data on health and food intake. There are no standard databases available that integrate food and drug monitoring, and thus methods that link large health survey data and pharmacy data are necessary to investigate effects of a combination of (functional) foods and drugs. By using such databases items like type of consumers, overall effectiveness of therapies, adherence to food and drug therapies, potential interactions on a behavioural or physiological level and long-term safety can be studied. In the near future this will become more and more important because the market for functional foods and dietary supplements with a health claim is expanding rapidly worldwide and consequently an increasing number of persons will use these products and combine them with their prescribed drugs.

\section{Conclusions}

In the present study we found that phytosterol/-stanolenriched margarine is effective in lowering TC, non-HDL-C and TC:HDL-C under customary conditions in both statin users and statin non-users. Recommended intake levels were achieved by only $9 \%$ of the subjects and resulted in a $4 \%$ decline in TC levels. Phytosterol/-stanol-enriched margarine can be recommended to statin non-users with normal to moderately increased serum TC and non-HDL-C concentrations who wish to maintain their cholesterol levels at, or reduce their cholesterol levels to, healthy levels. Statin users who wish to reduce their TC and non-HDL-C levels through diet can use the phytosterol/stanol-enriched margarines as an adjunct to their ongoing statin therapy. This might be especially beneficial for those subjects who do not achieve recommended TC and nonHDL-C target levels with statin monotherapy. Dietetics professionals should advise consumers on the appropriate 
intake level of the enriched margarines and should teach consumers how to use phytosterol/-stanol-enriched margarine as part of a balanced diet.

\section{Acknowledgements}

The study was funded by a grant from the National Institute for Public Health and the Environment (RIVM). The division of Pharmacoepidemiology and Clinical Pharmacology employing authors S.R.B.M.E. and O.H.K. has received unrestricted funding for pharmacoepidemiological research from GlaxoSmithKline, Novo Nordisk, the private-public funded Top Institute Pharma (www.tipharma.nl, includes co-funding from universities, government and industry), the Dutch Medicines Evaluation Board and the Dutch Ministry of Health. The authors N.d.J., C.J.M.R., J.G. and W.M.M.V. have no conflicts of interest to disclose. The Dutch Doetinchem Cohort Study was financially supported by the Ministry of Public Health, Welfare and Sports of the Netherlands and the National Institute of Public Health and the Environment (RIVM), Bilthoven. S.R.B.M.E., W.M.M.V. and O.H.K. designed the research. S.R.B.M.E. and O.H.K. analysed the data. All authors wrote the paper. S.R.B.M.E. and O.H.K. had primary responsibility for the final content. All authors read and approved the final manuscript. The authors thank the epidemiologists and field workers of the Municipal Health Service in Doetinchem for their contribution to the data collection for this study. W.M.M.V. was Project Leader; data management was performed by A. Blokstra MSc, P.E. Steinberger MSc and A.W.D. van Kessel MSc; logistic support was provided by J. Steenbrinkvan Woerden MSc and P. Vissink; and secretarial assistance was provided by E. van der Wolf.

\section{References}

1. Gotto AM Jr (1986) Treatment of hyperlipidemia. Am J Cardiol 57, 11G-16G.

2. Al-Daghri NM, Al-Attas OS \& Al-Rubeaan K (2007) The atherogenic and metabolic impact of non-HDL cholesterol versus other lipid sub-components among non-diabetic and diabetic Saudis. Lipids Health Dis 6, 9.

3. Cui Y, Blumenthal RS, Flaws JA et al. (2001) Non-highdensity lipoprotein cholesterol level as a predictor of cardiovascular disease mortality. Arch Intern Med 161, 1413-1419.

4. Frost PH \& Havel RJ (1998) Rationale for use of non-highdensity lipoprotein cholesterol rather than low-density lipoprotein cholesterol as a tool for lipoprotein cholesterol screening and assessment of risk and therapy. Am J Cardiol 81, 26B-31B.

5. Grundy SM (2001) Non-high-density lipoprotein cholesterol level as potential risk predictor and therapy target. Arch Intern Med 161, 1379-1380.

6. Orakzai SH, Nasir K, Blaha M et al. (2009) Non-HDL cholesterol is strongly associated with coronary artery calcification in asymptomatic individuals. Atherosclerosis 202, 289-295.
7. Packard CJ \& Saito Y (2004) Non-HDL cholesterol as a measure of atherosclerotic risk. J Atheroscler Thromb 11, 6-14.

8. Chelland Campbell S, Moffatt RJ \& Stamford BA (2008) Smoking and smoking cessation - the relationship between cardiovascular disease and lipoprotein metabolism: a review. Atherosclerosis 201, 225-235.

9. Fransen HP, de Jong N, Wolfs M et al. (2007) Customary use of plant sterol and plant stanol enriched margarine is associated with changes in serum plant sterol and stanol concentrations in humans. J Nutr 137, 1301-1306.

10. de Jong A, Plat J \& Mensink RP (2003) Metabolic effects of plant sterols and stanols. J Nutr Biochem 14, 362-369.

11. Marinangeli CP, Varady KA \& Jones PJ (2006) Plant sterols combined with exercise for the treatment of hypercholesterolemia: overview of independent and synergistic mechanisms of action. J Nutr Biochem 17, 217-224.

12. Plat J \& Mensink RP (2005) Plant stanol and sterol esters in the control of blood cholesterol levels: mechanism and safety aspects. Am J Cardiol 96, 15D-22D.

13. Plat J \& Mensink RP (2002) Increased intestinal ABCA1 expression contributes to the decrease in cholesterol absorption after plant stanol consumption. FASEB $J \mathbf{1 6}$, $1248-1253$.

14. Trautwein EA (2003) Proposed mechanisms of cholesterollowering action of plant sterols. Eur J Lipid Sci Technol 105, 171-185.

15. Eussen S, Klungel O, Garssen J et al. (2010) Support of drug therapy using functional foods and dietary supplements: focus on statin therapy. Br J Nutr 103, 1260-1277.

16. Demonty I, Ras RT, van der Knaap HC et al. (2009) Continuous dose-response relationship of the LDLcholesterol-lowering effect of phytosterol intake. $J$ Nutr 139, 271-284.

17. Katan MB, Grundy SM, Jones P et al. (2003) Efficacy and safety of plant stanols and sterols in the management of blood cholesterol levels. Mayo Clin Proc 78, 965-978.

18. Freemantle N \& Hessel F (2009) The applicability and generalizability of findings from clinical trials for healthpolicy decisions. PharmacoEconomics 27, 5-10.

19. Silverman SL (2009) From randomized controlled trials to observational studies. Am J Med 122, 114-120.

20. Cramer JA, Roy A, Burrell A et al. (2008) Medication compliance and persistence: terminology and definitions. Value Health 11, 44-47.

21. Liberopoulos EN, Florentin M, Mikhailidis DP et al. (2008) Compliance with lipid-lowering therapy and its impact on cardiovascular morbidity and mortality. Expert Opin Drug Saf 7, 717-725.

22. Verschuren WM, Blokstra A, Picavet HS et al. (2008) Cohort profile: the Doetinchem Cohort Study. Int J Epidemiol 37, $1236-1241$.

23. Ocke MC, Bueno-de-Mesquita HB, Goddijn HE et al. (1997) The Dutch EPIC food frequency questionnaire. I. Description of the questionnaire, and relative validity and reproducibility for food groups. Int J Epidemiol 26, Suppl. $1, \mathrm{~S} 37-\mathrm{S} 48$.

24. Ocke MC, Bueno-de-Mesquita HB, Pols MA et al. (1997) The Dutch EPIC food frequency questionnaire. II. Relative validity and reproducibility for nutrients. Int $J$ Epidemiol 26, Suppl. 1, S49-S58.

25. Voorlichtingsbureau voor de Voeding (1996) Stichting NEVO Nederlands Voedingsstoffenbestand 1996. The Hague: Voorlichtingsbureau voor de Voeding.

26. Herings RM, Bakker A, Stricker BH et al. (1992) Pharmacomorbidity linkage: a feasibility study comparing morbidity in two pharmacy based exposure cohorts. J Epidemiol Community Health 46, 136-140.

27. Institute for Drug Outcome Research (2002) PHARMO Records Linkage System. http://www.pharmo.nl/ (accessed November 2009). 
28. Hepburn P, Howlett J, Boeing $\mathrm{H}$ et al. (2008) The application of post-market monitoring to novel foods. Food Chem Toxicol 46, 9-33.

29. WHO Collaborating Centre for Drug Statistics Methodology (2010) Guidelines for ATC classification and DDD assignment. http://www.whocc.no/filearchive/publications/ 2010guidelines.pdf (accessed November 2009).

30. Penning-van Beest FJ, Termorshuizen F, Goettsch WG et al. (2007) Adherence to evidence-based statin guidelines reduces the risk of hospitalizations for acute myocardial infarction by 40\%: a cohort study. Eur Heart J 28, 154-159.

31. Houterman S, Verschuren WM, Oomen CM et al. (2001) Trends in total and high density lipoprotein cholesterol and their determinants in The Netherlands between 1993 and 1997. Int J Epidemiol 30, 1063-1070.

32. Greenland S (1989) Modeling and variable selection in epidemiologic analysis. Am J Public Health 79, 340-349.

33. Ketomaki A, Gylling $\mathrm{H} \&$ Miettinen TA (2005) Noncholesterol sterols in serum, lipoproteins, and red cells in statin-treated FH subjects off and on plant stanol and sterol ester spreads. Clin Chim Acta 353, 75-86.

34. de Jong N, Zuur A, Wolfs MC et al. (2007) Exposure and effectiveness of phytosterol/-stanol-enriched margarines. Eur J Clin Nutr 61, 1407-1415.

35. Simons LA (2002) Additive effect of plant sterol-ester margarine and cerivastatin in lowering low-density lipoprotein cholesterol in primary hypercholesterolemia. Am J Cardiol 90, 737-740.

36. Anon. (1984) The Lipid Research Clinics Coronary Primary Prevention Trial results. II. The relationship of reduction in incidence of coronary heart disease to cholesterol lowering. JAMA 251, 365-374.

37. Law MR, Wald NJ \& Thompson SG (1994) By how much and how quickly does reduction in serum cholesterol concentration lower risk of ischaemic heart disease? $B M J$ 308, 367-372.

38. Crowley LV (2009) An Introduction to Human Disease Pathology and Pathophysiology Correlations, 8th ed. Sudbury: Jones and Bartlett Publishers.

39. Hallikainen MA, Sarkkinen ES, Gylling H et al. (2000) Comparison of the effects of plant sterol ester and plant stanol ester-enriched margarines in lowering serum cholesterol concentrations in hypercholesterolaemic subjects on a low-fat diet. Eur J Clin Nutr 54, 715-725.

40. Weststrate JA \& Meijer GW (1998) Plant sterol-enriched margarines and reduction of plasma total- and LDLcholesterol concentrations in normocholesterolaemic and mildly hypercholesterolaemic subjects. Eur J Clin Nutr $\mathbf{5 2}$, 334-343.

41. Noakes M, Clifton P, Ntanios F et al. (2002) An increase in dietary carotenoids when consuming plant sterols or stanols is effective in maintaining plasma carotenoid concentrations. Am J Clin Nutr 75, 79-86.

42. O'Neill FH, Brynes A, Mandeno R et al. (2004) Comparison of the effects of dietary plant sterol and stanol esters on lipid metabolism. Nutr Metab Cardiovasc Dis 14 $133-142$

43. de Jong A, Plat J, Ltjohann D et al. (2008) Effects of longterm plant sterol or stanol ester consumption on lipid and lipoprotein metabolism in subjects on statin treatment. $\mathrm{BrJ}$ Nutr 100, 937-941.

44. O'Neill F, Sanders TAB \& Thompson G (2005) Comparison of efficacy of plant stanol ester and sterol ester: short-term and longer-term studies. Am J Cardiol 96, 29D-36D.

45. Wolfs M, de Jong N, Ocke MC et al. (2006) Effectiveness of customary use of phytosterol/-stanol enriched margarines on blood cholesterol lowering. Food Chem Toxicol 44, 1682-1688. 